\title{
Opportunity and Challenge of 3D Printing-based Customized Design
}

\author{
Ding Zhou \\ School of Industrial Design \\ Nanjing University of the Arts \\ Nanjing, China
}

\begin{abstract}
With application of the 3D printing technology as a tool for prototyping, is it possible to accelerate 3D printed consumer products through customizing geometries, which is one of the objectives of design for additive manufacturing/3D printing? Through application of a pair of theoretical bases of Value Co-creation and Service Innovation, an integrated research was carried out to figure out opportunity and challenge of 3D printing-based customized design. Research of the online 3D co-creation cases demonstrates the model of this service type. An exploration study based on implementation of one service prototype, furthermore, develops insight into either effect or impact of 3D printing-based customized design on designer/service provider and customer.
\end{abstract}

Keywords-customized design; $3 D$ printing; co-creation; service innovation; mass customization

\section{INTRODUCTION}

Customized design (hereinafter referred to as CD) represents the service process, wherein a product perfectly satisfies the desire of a customer or a group. As one of the objectives of design for additive manufacture/3D printing, customized geometry can facilitate application of 3D printing technology to gradually achieve product customization [1].

What type of service is capable of putting 3D printing into CD? The answer is co-creation. According to a business strategy which focuses on customer experience and interactive relationships, co-creation is defined as an active, creative and social collaborative process between producers and users and aims to create values for customers [2]. In comparison with scanning-based customization, co-creation provides a flexible format, wherein 3D printing technology is applied more efficiently and extensively. From the industrial perspective, co-creation therefore is expected to obtain a fastgrowing market volume [3][4]. Nowadays, a variety of online 3D co-creation applications are released on the Internet to satisfy value creation for customers. Through the web-based 3D visualized interface, a customer can create and explore his or her own product, and can then obtain the tangible outcome which will be 3D-printed by the service supplier.
Despite of the rapid growth of online 3D co-creation application, researches rarely focus on developing insight into 3D printing-based CD. In 2015, Rayna, Striukova, and Darlington investigated the changes brought by online 3D printing platforms to co-creation and user innovation. The authors concluded that co-creation transforms consumers into prosumers, and 3D printing technology helps co-creation give full play to its potential [5]. Rayna et al. also suggested: "for this to happen, adequate co-creation platforms shall be built and this requires full understanding the different aspects of co-creation, the consequences of pro-consumption and the key roles of information systems." Nevertheless, the prior research may not be beneficial enough for designers and service providers who are involved in this new trend of CD.

This integrated research aims to figure out the opportunity and challenge of 3D printing-based $\mathrm{CD}$. Based on a pair of theoretical bases of Value Co-creation and Service Innovation, the first section presents case studies of the selected online 3D co-creation applications, in order to induce a model involving how 3D printing-based CD works. In the second section, an exploration study was carried out through implementation of one prototype of 3D co-creation service. Evidences collected from both the research processes and the results develop insight into $3 \mathrm{D}$ printingbased CD from the perspective of service market.

\section{THEORETICAL BASES AND KEY CONCEPT}

\section{A. Den Hertog's Model of Service Innovation}

A pair of theoretical bases was applied to build a systematic framework in this research. The first one is the Den Hertog's model of service innovation (hereinafter referred to as the Den Hertog's model). As shown in "Fig. 1", the model presents four dimensions including new service concept, new client interface, new service delivery system, and technological options [6]. This framework manifests service innovation and discusses the practical development of new services, such as the 3DPS co-creation, namely the topic of this paper. 


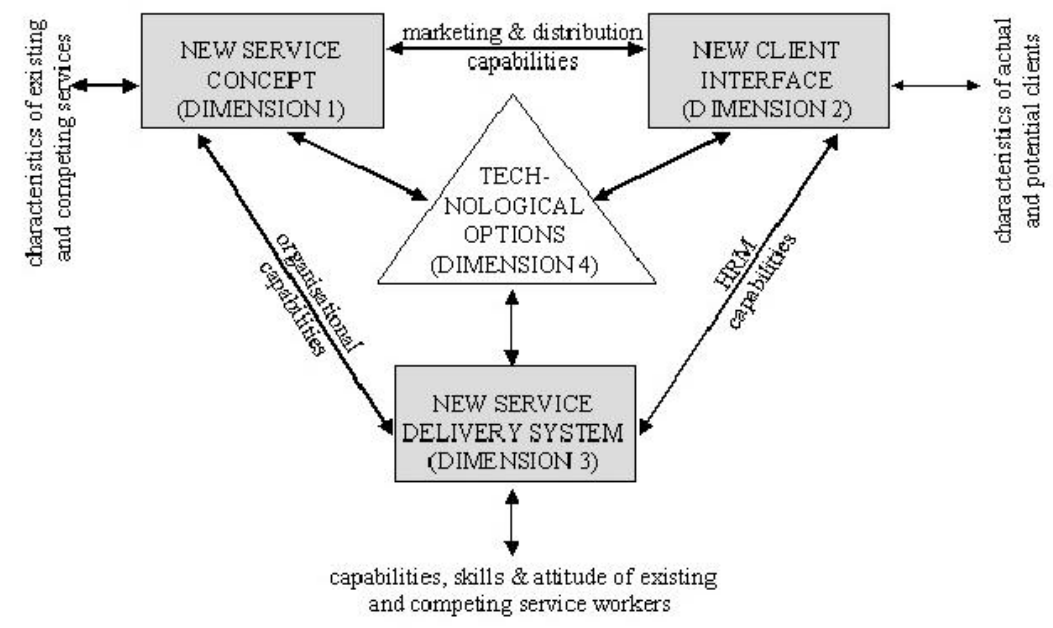

Fig. 1. Den Hertog's model of service innovation.

\section{B. Building Blocks of Interactions for Value Co-creation}

Another model, as shown in "Fig. 2", displays the building blocks of interactions for value co-creation: dialogue, access, risk-benefits, and transparency (hereinafter referred to as the DART model). It presents the components in basis construction, which are necessary for interactions between a consumer and a service provider [7]. Dialogue represents the interaction between a customer and a firm. Access refers to that a customer is allowed to get access to data. Risk-benefits remind us to control risk and gaps. Transparency guarantees accessibility of information.

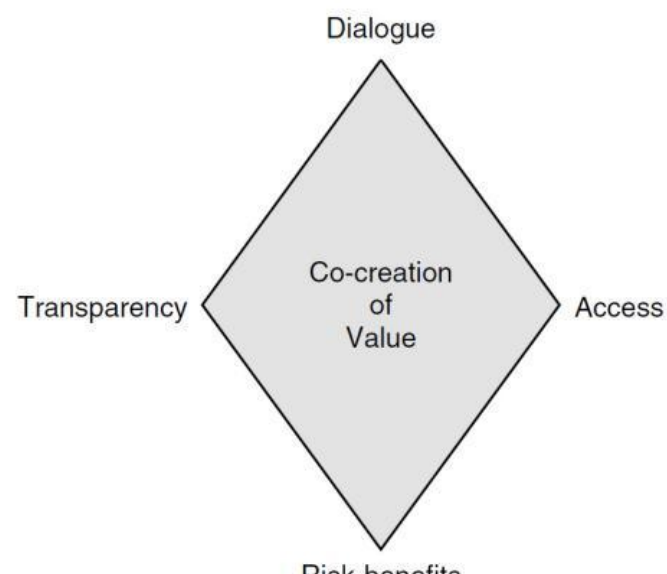

Risk-benefits

Fig. 2. Building blocks of interactions for value co-creation.

\section{3D Printing-based CD}

In this paper, 3D printing-based $\mathrm{CD}$ is defined as follows: a variety of customization services aiming to create a $3 \mathrm{D}$ printable digital model which could satisfy customers' tastes. Both the online 3D co-creation application and the related service in a real-world scenario are commonly deemed as typical examples. However, this research suggests that ambiguous types and definite types of online 3D co-creation application shall be distinguished according to the service goal.

The former, like TINKEDCAD design application (https://www.tinkercad.com/) displayed in "Fig. 3", provides users with a completely open innovation environment, wherein any possible work might be created and 3D-printed then. The latter refers to flexible formats employed by users to reach a specific design goal, such as jewelry, decor, and characters. "Fig. 4" shows KINEMATICS (http://n-e-r-v-ou-s.com/kinematicsHome/), namely an online design application for designing and 3D printing of customized bracelets. Its pieces were based on "physical simulation of springs arranged in a cellular mesh" [8]. With regard to the Nervous System, a US-based generative design studio launches KINEMATICS and a broad range of 3D printing applications. These definite-type samples were taken as the current research objects, because they present a definite scope of services.

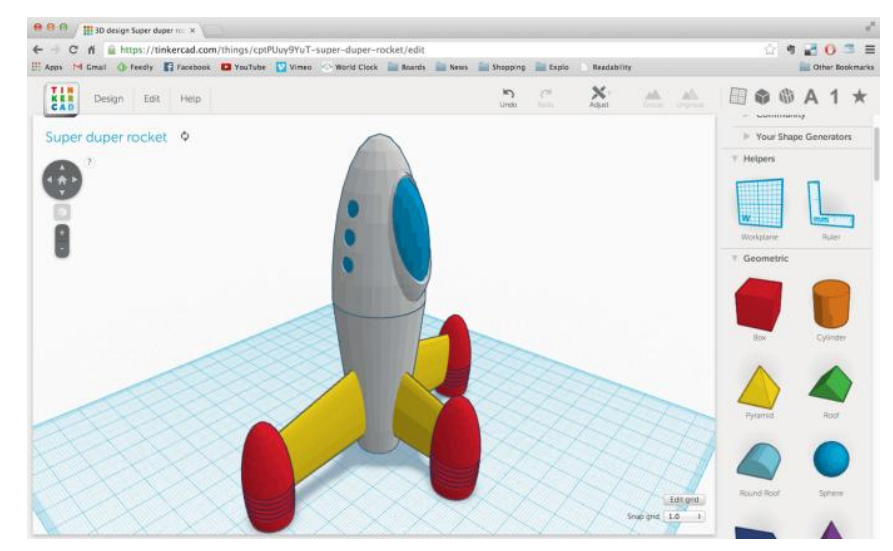

Fig. 3. TINKEDCAD design application. 
Kinematics@ home

mingate

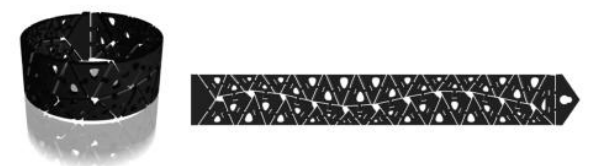

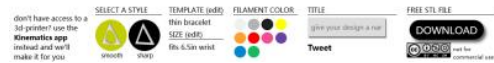

Fig. 4. KINEMATICS design application.

\section{RESEARCH DESIGN AND METHODS}

The research aims to explore the opportunity and challenge of $3 \mathrm{D}$ printing-based $\mathrm{CD}$. At the beginning, the author expected to introduce a model of online 3D cocreation application. In order to explore the solutions, evidence shall be collected through observation and description of the definite-type samples. As a type of emerging technology application, the number of targeted cases is still limited to a great extent. Therefore, an inductive approach based on qualitative case study was adopted [9][10].

TABLE I. CASE STUdY FRAMEWORK

\begin{tabular}{|l|l|l|l|}
\hline \multirow{2}{*}{ Sample } & \multicolumn{2}{|c|}{ Detailed items } & Evidences \\
\hline \multirow{2}{*}{$\begin{array}{l}\text { Items of Den Hertog's } \\
\text { model }\end{array}$} & Service concept & \\
\cline { 3 - 4 } & Client interface & \\
\cline { 3 - 4 } & Service delivery system & \\
\cline { 3 - 4 } & Technological options & \\
\cline { 3 - 4 } & Items of DART model & Dialogue & \\
\cline { 3 - 4 } & Access & \\
\cline { 3 - 4 } & Risk-benefits & \\
\cline { 3 - 4 } & Transparency & \\
\hline
\end{tabular}

In order to collect systematic evidence of the selected case, this task was performed at two main parts based on the Den Hertog's model which contained service concept, client interface, service delivery system, technological options, as well as the DART model which contained dialogue, access, risk-benefits, transparency. As shown in "Table I", a framework was developed, wherein the essential components of 3D printing-based CD are investigated and defined. Based on case studies, a model of online 3D co-creation application was then induced. With application of this model, the author carried out an exploration study to explore either effect or impact of 3D printing-based $\mathrm{CD}$ on designer/service providers and customers. This kind of research method is deemed to be most helpful for generation of expected findings.

\section{CASE Studies ON ONLINE 3D Co-CREATION APPLICATIONS}

\section{A. Case Selection}

With regard to the case study samples, this chapter selected four online 3D co-creation applications according to these standards. Firstly, as mentioned above in Chapter II, the goal of samples must be clear and definite. Secondly, selected cases should represent a specific category respectively. In particular industries, this criterion facilitates collection of adequate evidence from a responding 3D cocreation process. As shown in "Table II", samples are classified into four categories including Jewelry \& Fashion, Decor \& Houseware, Characters \& Creatures, and Terrain \& Geography. Thirdly, these cases should be set up by different enterprises. Therefore, various co-creation features would be involved in the following survey.

TABLE II. CASE Study SAmples

\begin{tabular}{|c|l|l|}
\hline Samples & \multicolumn{1}{|c|}{ Categories } & \multicolumn{1}{c|}{ Summaries } \\
\hline RADIOLARIA & $\begin{array}{l}\text { Jewelry \& } \\
\text { Fashion }\end{array}$ & $\begin{array}{l}\text { A co-creation service which provides a } \\
\text { customized earring and carries out 3D } \\
\text { printing to it for the customer }\end{array}$ \\
\hline $\begin{array}{c}\text { COOKIE } \\
\text { pASTER }\end{array}$ & $\begin{array}{l}\text { Decor \& } \\
\text { Houseware } \\
\text { customized cookie cutter for the } \\
\text { customer. The co-created outcome is } \\
\text { ready for 3D printing through the } \\
\text { customer downloading. }\end{array}$ \\
\hline $\boldsymbol{P U P W O R K S H O P}$ & $\begin{array}{l}\text { Characters \& } \\
\text { Creatures }\end{array}$ & $\begin{array}{l}\text { A co-creation service which provides a } \\
\text { customized toy pup and carries out 3D } \\
\text { printing of it for the customer }\end{array}$ \\
\hline $\begin{array}{l}\text { BENGLER } \\
\text { TERRAFAB }\end{array}$ & $\begin{array}{l}\text { Terrain \& } \\
\text { Geography }\end{array}$ & $\begin{array}{l}\text { A co-creation service which provides a } \\
\text { customized Norwegian miniature } \\
\text { landscape and carries out 3D printing of } \\
\text { it for the customer. The co-created } \\
\text { outcome also gets ready for 3D printing } \\
\text { through the customer downloading. }\end{array}$ \\
\hline
\end{tabular}

\section{B. Collection and Analysis of Evidences}

Through summarization of the survey results based on selected samples about online 3D co-creation, the detailed case evidences are listed in four tables, which are taken as supporting materials on the reverse side of this article. The evidence was analyzed to define the essential components of online 3D co-creation application.

First and foremost, three accesses mainly facilitate the structure of this type of $3 \mathrm{D}$ printing-based $\mathrm{CD}$. These accesses enable a customer to know service concept, cocreating geometry, and accepting service delivery. Secondly, the interfaces bring corresponding dialogues between accesses and the customer so as to reach every process goal. In particular, the WebGL-based co-creating interface displays some design variables, which can be adjusted by the customer for personal creation. Thirdly, the outcome of cocreation refers to a $3 \mathrm{D}$ printed artifact or a $3 \mathrm{D}$ digital model. The service provider produces the co-created geometry through application of the 3D printing technology, and delivers it to the customer. Sometimes, the 3D model file is available for downloading of the customer. Last but not least, transparency plays an important role in stabilizing the system of online 3D co-creation application as it helps the customer obtain explicit understanding of co-creation, purchase and downloading.

\section{Findings}

As found in this chapter, the system of online 3D cocreation application is composed of three dialogues consisting of related accesses and interfaces, and the to-be3D printed outcome. In the context of co-creation service, $3 \mathrm{D}$ printing technology performs outstandingly in production of customized artifacts. A lot of online 3D co-creation 
applications have been achieved in these emerging industries. However, studies about how3D printing-based CD works are quite insufficient. In this chapter, the holistic multiple-case study was carried out to find its essential components. Investigation findings showed that online 3D co-creation application was composed of three dialogues including service concept, co-created geometry, and service delivery, as well as the service outcomes such as the 3D printed artifact or its digital file.

In conclusion, the model of online 3D co-creation application is presented in the "Fig. 5". This model has two basic tiers, with three components in the interface tier and three components in the access tier. In order to build an online 3D co-creation application, the service provider needs to follow four steps, wherein three dialogues and one

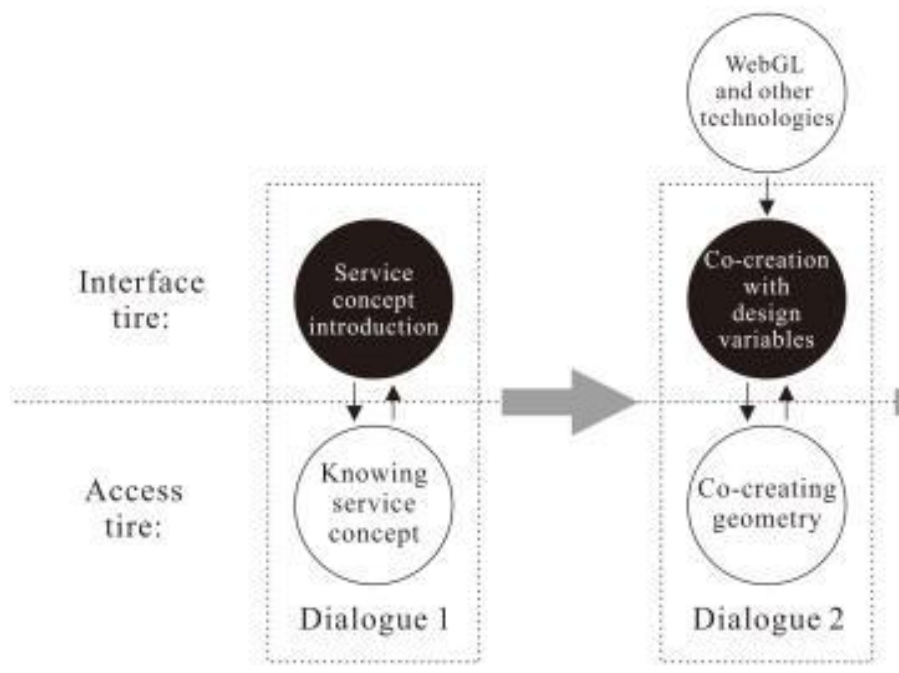

outcome group are facilitated. At the first step, the dialogue 1 with the interface of service concept introduction and the access to understand it is constructed. At the second step, the related dialogue is facilitated based on the interface of cocreation with design variables and the access of geometry cocreation. Here, WebGL and other technologies generate 3D graphics on this definite process. The third step requires the service provider to construct a dialogue for service delivery, involving two components including the interface of purchasing or downloading, and the access of accepting service delivery. At the fourth step, the customized artefact needs to be 3D-printed and then delivered to a customer; or a 3D digital model shall get ready for downloading. In addition, the service provider needs to guarantee the transparency as it enables a customer to know the possible benefits or risks exactly.

Fig. 5. Model of online 3D co-creation application.

\section{EXPLORATION STUdY THROUGH IMPLEMENTING A 3D PRINTING-BASED CUSTOMIZED DESIGN}

\section{A. Preparation for Exploration Study}

In order to explore effect and impact of $3 \mathrm{D}$ printingbased $\mathrm{CD}$ on designer/service providers and customers, an exploration study was implemented in this section. Exploration study refers to a type of research method aiming to discuss newly-developed conceptions. It particularly suits some emerging topics, like 3D printing-based $\mathrm{CD}$, in which a limit number of cases could be targeted, while a few of researches are involved. Its research findings normally establish a systematic background for a series of future studies.

In Chapter IV, the model of online 3D co-creation application describes four sections for establishing a CD service. The author here applied its structure to create a prototype of $3 \mathrm{D}$ printing-based $\mathrm{CD}$ for personalized ring, including corresponding steps: understanding of rules of cocreation, co-creating ring, confirmation of the co-created ring, and $3 \mathrm{D}$ printing of the co-created ring.

\section{B. Process of Implementation}

A group of eight customers were involved in a cocreation process, wherein the ring which satisfies their needs is customized, and then personalized commodities are produced through $3 \mathrm{D}$ printing. This $3 \mathrm{D}$ printing-based $\mathrm{CD}$ was implemented through the four steps as follows:

1) Understanding rules of co-creation: The author introduced what is co-creation and how to co-create a personalized ring. In addition, knowledge of $3 \mathrm{D}$ printing technology was presented.

2) Co-creating ring: As shown in "Fig. 6", the author firstly guided customers to sketch patterns in a provided rectangle. Customers then photographed their graphic works with a phone camera. The data was further transformed into 3D geometries through computer-aided design software.

3) Confirming the co-created ring: The design results were rapidly displayed in a render image, so that customers could confirm and purchase the customized rings.

4) $3 D$ printing the co-created ring: In this service of $3 \mathrm{D}$ printing-based $\mathrm{CD}$, customized digital geometries were 
directly produced by a metal 3D printer. Surface finishing was also used to ensure high quality of products.

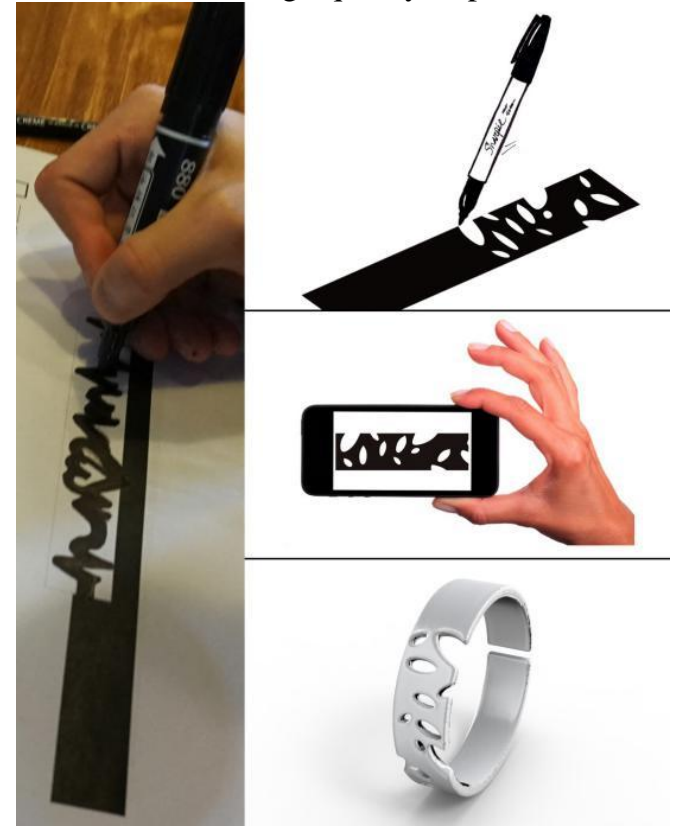

Fig. 6. Process of co-creating ring.

\section{Results and Findings}

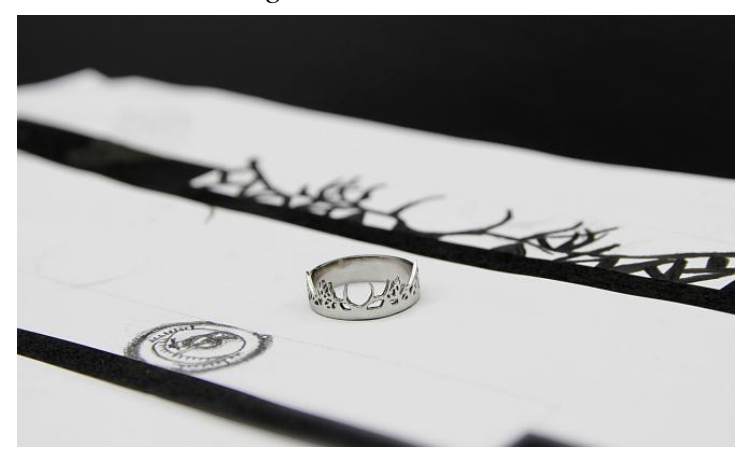

Fig. 7. Co-created ring through $3 \mathrm{D}$ printing-based customized design.

This 3D printing-based CD was successfully implemented as one of the customized rings, as shown in Fig.7. Research findings include related effects and impacts on two involved sides of this service prototype: designer/service providers and customers. 3D printing-based $\mathrm{CD}$ drives experiential consumption business that enables customer to explore and create their own designs. Digital modeling technique helps build fully-customized geometry for ending 3D printed product which expresses personal emotion. For designer/service provider with a digital model, 3D printing-based $\mathrm{CD}$ lends them an edge to bypass the traditional supply chain and manufacture products themselves. That means 3D printing enhances designer/service provider a capability of design and production. In this context, the role of designer/service provider is transformed from creative talent to service planner. Additionally, 3D printing represents a type of datadriven technology, in which any activity is compelled by data rather than by personal experience. Therefore, interaction between customer and designer/service provider can be of high efficiency when it is embedded in a community activity or the Internet.

\section{CONCLUSION}

As service market continues to address the growing need for $\mathrm{CD}$ and attempt to put 3D printing technology into related co-creation projects, research needs to address not only the value but also the opportunity and challenge of $3 \mathrm{D}$ printing-based $\mathrm{CD}$. In order to figure out how this type of service works, this paper firstly brought a case study on a series of 3D co-creation applications for inducing the model of 3D printing-based CD. Further, an exploration study through implementing a 3D Printing-based CD developed insight into service effect and impact on designer/service provider and customer.

There are three main opportunities of for designer/service provider engaging in. First of all, it is a significant chance to follow emerging consumption trend that moving towards a personalized economy, and away from the one-fit-for-all solutions. Second, in this age of the Internet, a successful 3D Printing-based CD like KINEMATICS co-creation application can distribute numerous customized products. Third, it is also a positive chance to collect data regarding customers' preference in order to meet their tastes more closely. Last but not least, adding 3D Printing-based CD to service process is an excellent way to add value to business. However, a variety of challenges also need to be emphasized. Compared with conventional injection molding, 3D printing brings a relative expensive cost. Negatively, customers have to afford a period of several days until receive the customized products, though they are already purchased. Because time is consumed by processes including additive manufacturing, surface finishing, shipping, etc. Effective marketing also needs to be dealt with by designer/service provider. Practical problems, like types of 3D Printing-based $\mathrm{CD}$, 3D co-creation experience evaluation, economic or social impact of 3D Printing-based CD, need to be addressed in the future research.

\section{ACKNOWLEDGMENT}

This article refers to a result of the Philosophy and Social Science Research Projects of Universities in Jiangsu Province that "Internet+3D Printing: Research on Cocreation for Cultural and Creative Products in Industrial Chain of 3D Printing". The project number is 2016SJD760015, and its code is DGZDDST16.

\section{REFERENCES}

[1] GIBSON, I., ROSEN, D. W., \& STUCKER, B. (2010). Additive manufacturing technologies. New York: Springer.

[2] PILlER, F. T., \& TSENG, M. M. (Eds.). (2010). Handbook of research in mass customization and personalization (Vol. 1, p. 188). Singapore: World scientific.

[3] DERVOJEDA, K., VERZIJL, D., NAGTEGAA, F., LEONGTON, M., ROUWMAAT, E., MONFARD, E., \& FRIDERES, L. (2014). Design for innovation: co-creation design as a new way of value creation. European Union.

[4] SANDERS, E. B. N., \& STAPPERS, P. J. (2008). Co-creation and the new landscapes of design. Co-design, 4(1), 5-18.4. 
[5] RAYNA, T., STRIUKOVA, L., \& DARLINGTON, J. (2015). Cocreation and user innovation: The role of online 3D printing platforms. Journal of Engineering and Technology Management, 37, 90-102..

[6] HERTOG, P. D. (2000). Knowledge-intensive business services as co-producers of innovation. International Journal of Innovation Management, 4(04), 491-528.

[7] PRAHALAD, C. K., \& RAMASWAMY, V. (2004). Co-creation experiences: The next practice in value creation. Journal of interactive marketing, 18(3), 5-14.

[8] DERRINGE, J. (2010) Cell Cycle by Nervous System. Retrieved October 11, 2010, from: http://design-milk.com/deconstruction-cellcycle-by-nervous-system/.

[9] EISENHARDT, K. M. (1989). Building theories from case study research. Academy of management review, 14(4), 532-550.

[10] YIN, R. K. (2013). Case study research: Design and methods. Sage publications. 